\title{
Characterising forest wind profiles for utilisation in fire spread models
}

\author{
$\underline{\text { K. Moon }}{ }^{\mathrm{ab}}$, T.J. Duff ${ }^{\mathrm{a}}$, K.G. Tolhurst ${ }^{\mathrm{a}}$ \\ ${ }^{a}$ Department of Forest and Ecosystem Science, Melbourne School of Land and Environment, University of \\ Melbourne, Creswick, Victoria, Australia \\ ${ }^{b}$ Bushfire Cooperative Research Centre, Melbourne, Victoria, Australia
}

Email:k.moon@student.unimelb.edu.au

\begin{abstract}
Fire behaviour is strongly affected by wind speed and direction. Wind affects fire spread rate bending the flames closer to unburnt fuel, increasing the rate of combustion and by blowing embers ahead of the main fire front lighting spotfires. Stronger winds blow flames forward, lowering the flame angle and subsequent distance between the flame and the fuel. In open areas there is typical a logarithmic vertical wind profile; winds become faster as height increases. However forest vegetation disrupts wind flow, and a logarithmic profile cannot be assumed.

When predicting forest fire spread, wind reduction factors are typically used to reduce open area wind speeds to the more sheltered sub-canopy winds that directly affect fire spread. These methods typically assume a consistent vertical wind profile that does not change with wind speed. In this study we investigated these assumptions. We characterised the variation in wind speed at different heights in different vegetation types and at different open area wind speeds. To do this, we used cup anemometers to measure the horizontal wind speed at different heights in four differently structured forest areas. Our results show that the use on a single wind reduction factor is a gross over-simplification; horizontal wind speeds can vary by a factor of three depending of the height above ground. We have also found that even for a given height, the wind reduction factor can vary by a factor of two or more depending on the strength of the winds in the open. This is in addition to a factor of 10 or more variation in wind speed between different vegetation types.
\end{abstract}

The variation in wind speed in different vegetation type, height above ground and wind speed in the open means that there is potentially a large margin of error in predicting fire behaviour using wind speeds measured or forecast for $10 \mathrm{~m}$ in the open for fires in forests or shrublands. Some strategies for improving estimates of wind speed for fire spread prediction are discussed.

Keywords: $\quad$ Fire behaviour, fire spread rate, vegetation structure 


\section{INTRODUCTION}

\subsection{Importance of Wind to Fire}

There are three key factors that influence fire behaviour; topography, weather and fuels (Agee 1993). Of these, weather, and in particular, wind is responsible for much of the variability (Brun et al. 2012). Wind is fundamentally involved in heat transfer between fuels, including pre-ignition heating and flame transfer (Nelson Jr et al. 1988). Wind affects fire spread rate by bending the flames closer to the unburnt fuel, increasing the rate of combustion and by blowing embers ahead of the main fire front lighting spotfires. Stronger winds blow flames forward, lowering the flame angle and distance between the flame and the fuel. Consequently wind is a crucial element in determining how and where fires will travel.

The ability to rapidly predict fire spread patterns is extremely important for the management of wildfires. Advance knowledge of potential impacts can provide for controlled evacuation, strategic asset protection and assist in planning suppression activities. Numerous models have been developed to forecast fire behaviour; processing inputs based on the drivers of fire behaviour; fuel (including fuel loads, structure and moisture content), topography (including slope and aspect) and weather (including temperature, relative humidity and wind speed) (Sullivan 2009). While early models simply provided indices of fire spread, models that can create spatial forecasts of fire characteristics have been recently developed. A number of these, including FARSITE (Finney 2004) and PHOENIX Rapidfire (Tolhurst et al. 2008) have been adopted operationally by land management agencies. In these models, wind speed is a critical input for determining major fire spread parameters including rate of spread, fireline intensity and fire shape.

Where there is complex vegetation, such as forests, the free passage of wind is impeded, resulting in turbulence that affects wind speeds both above and within the vegetation. Under mild to moderate fire conditions, fires typically burn below the forest canopy in a micro-environment that will be somewhat sheltered from 'open' wind conditions. Despite the critical importance of wind to the spread of forest fires, research is limited on the magnitude and patterns of wind variation in forests (Pereira et al. 1980).

\subsection{The Vertical Wind Profile}

Wind speeds are typically described as wind profiles; expressions of horizontal wind speed with height (Oke 1987). In an open environment (such as a grassland), the wind profile typically has a logarithmic shape, with wind speed increasing with height (Downey 2006) (Figure 1). However, when more vertically structured vegetation types, such as forests, the wind flow is interrupted, producing eddies and turbulence. In addition, a certain proportion of wind momentum is absorbed by vegetation, resulting in a wind speed reduction (Grant

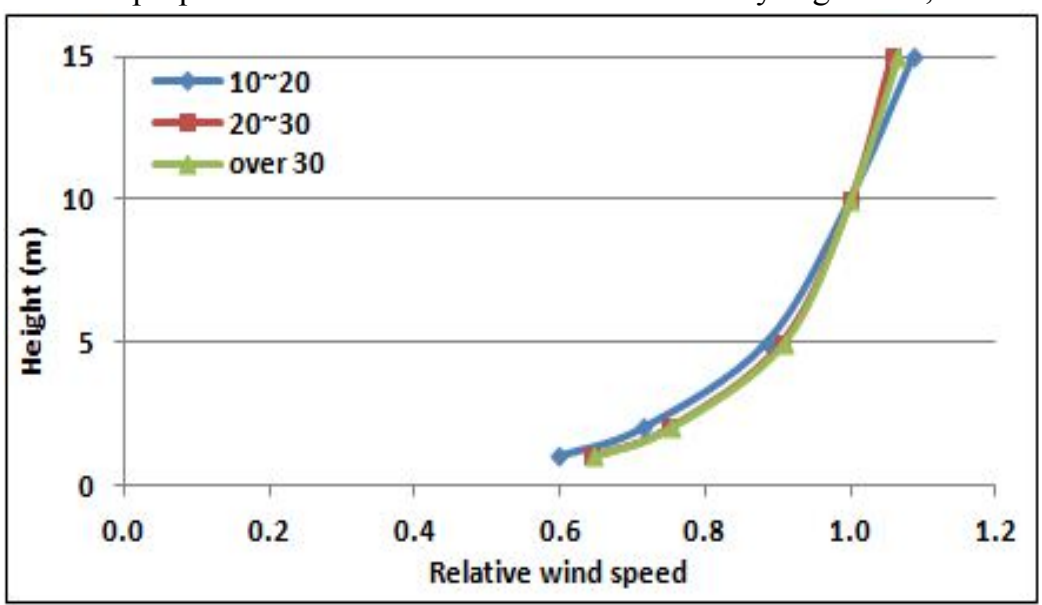

Figure 1 Typical wind speed increase pattern in an open environment in different speed ranges. Note that there is a consistent structure of wind at all heights with increasing wind speed. et al. 1998). Numerous vegetation properties including leaf density, vegetation porosity and flexibility affect the way plants create drag and interact with wind flow (Grant 1985). These properties are a consequence of the specific structural arrangement of vegetation elements including branches, boles, stems and leaves. This interaction results in a deviation from the logarithmic pattern and can produce complex wind profiles where wind speeds vary substantially with height (i.e.Fons (1940)).

Vegetation structure varies greatly between vegetation types. For example, crops have a relatively simple structural profile with little change with height within the crop (Cionco 1978). Open forests typically have a dense canopy layer and a moderately dense shrub layer separated by a relatively sparse layer consisting of primarily of tree boles. Rainforest is typically very dense and consists of multiple vegetation strata (Smith 1992). In forests, wind speed generally decreases with a height under the canopy layer as momentum transport will be weakened by the vegetation components in each layer. However, the rate of decrease with height will be dependent on the corresponding vegetation structural characteristics (Oliver 1971; Raynor 
1971). It is important when forecasting fire spread to understand the winds that are influencing the flames; a low intensity forest fire will have a low flame height and will be more sheltered than a fire with a high flame height. As a fire increases in intensity, it will be affected by different parts of the vertical wind profile and its behavior will change accordingly. To properly predict fire behaviour, it is important to understand the winds that influence a fire; the effective wind speed that is influencing the flames (typically defined as the midflame height).

\subsection{Current Treatment of Winds in Fire Spread Models}

To enable the prediction of forest fire spread, indices have been developed to allow the representation of wind speeds in a forest or shrubland based on vegetation density and forecast wind speed for a standard reference height $(10 \mathrm{~m})$ in an open environment. Wind speeds are reduced by a value, typically assumed to be constant for the entire vertical profile of the forest; the 'wind reduction factor (WRF)' (Cionco 1972; Rothermel 1972). For example, in tall eucalyptus forest, there is a reduction in wind speed of a ratio of 10:1 between the open area winds and a height of $2 \mathrm{~m}$ within the forest (McArthur 1967). These WRF values are used to modify forecast wind speeds to provide effective forest wind speeds for fire spread prediction. In the USA, a similar index, the 'wind adjustment factor' (WAF) is used to find the 'mid-flame' wind speed for fire modelling (Andrews 2012). These factors can be empirically determined using measured vegetation structure such as crown ratios (crown height/ overall tree height), stocking level (dense and open) and age class (Albini et al. 1979; Cruz et al. 2010; Andrews 2012). A common assumption with the application of these factors is that the vertical wind profile within a forest is uniform (although the wind adjustment factor does account for lower speeds very close to the ground) (Figure 2).

As fires of different intensities will have flames of different heights and wind profiles can be complex in forests (Andrews 2012), the winds that drive fire spread may not necessarily be the same as flame heights increase. Consequently, the use of constant WRFs may be misleading unless the forest wind profiles are entirely uniform.

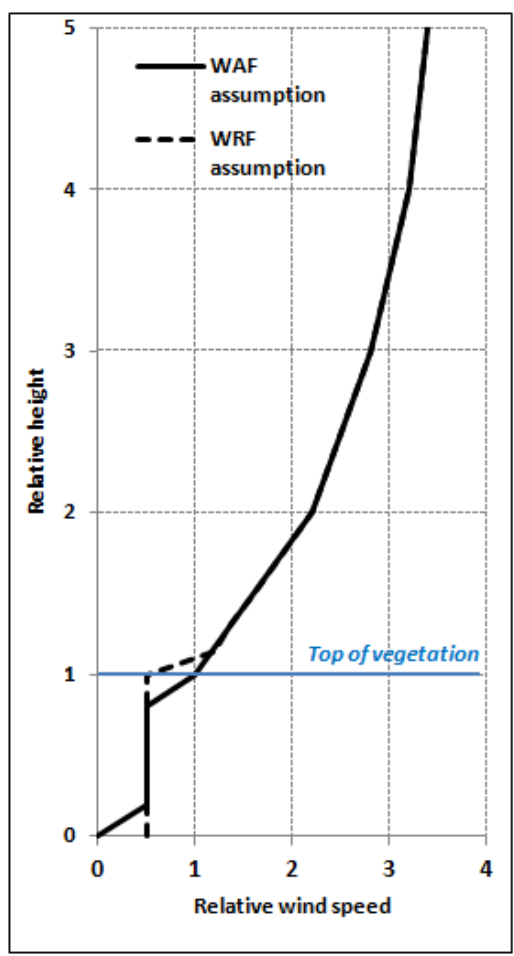

Figure 2 Assumed wind profile within and over vegetation for WAF and WRF theories (modified from Andrews (2012)). Values of $x$ and $y$ axis were standardised by top of vegetation values.
The aim of this study is to 1) evaluate the shape of vertical wind profiles in different vegetation types, and 2) evaluate the consistency of wind profiles as the open area wind speed changes. We intend to evaluate the suitability of applying consistent WRFs for fire spread models in complex forest vegetation.

\section{METHOD}

\subsection{Study Sites}

Four sites were selected near Creswick, Victoria, Australia, each in different vegetation types (Mature pine plantation, regrowth open forest, mature open forest and open grassland). To avoid topographic influences such as wind channelling (Dupont et al. 2012), we selected relatively flat areas.

\subsection{Wind Measurement}

Winds were measured using guyed-masts with horizontal cup anemometers mounted at set heights $(1,2,5,10$ and $15 \mathrm{~m})$. Five towers were used to measure wind concurrently at each location. The sensor installations were left at each site for approximately a month.

Above canopy wind speeds were measured using 3 cup anemometers at $h, h+5 m, h+10 m(h=a v e r a g e$ canopy height $)$ that were installed on a $35 \mathrm{~m}$ fixed tower to obtain a reference wind profile. The $\mathrm{h}+10 \mathrm{~m}$ measurement was assumed to represent open area wind speeds. The $35 \mathrm{~m}$ tower was used to collect reference data for all other locations.

The data logging frequency for wind sensors were set to 2 minutes. This period is congruent with the observed fire residence times of between 0.5 and 2 min (Stocks et al. 2004; Taylor et al. 2004). Forest wind measurements were standardized by the $\mathrm{h}+10 \mathrm{~m}$ measurements and normalised by canopy height. Vertical wind profiles were plotted, with separate lines for winds in the range of 10-20, 20-30 and over 
$30+\mathrm{km} / \mathrm{h}$. Winds over $30 \mathrm{~km} / \mathrm{h}$ in the mature open forest were not described as the measurement frequency was below the level of the desirable confidence level ( $90 \%$; a minimum of 30 measurements).

\section{RESULTS AND DISCUSSION}

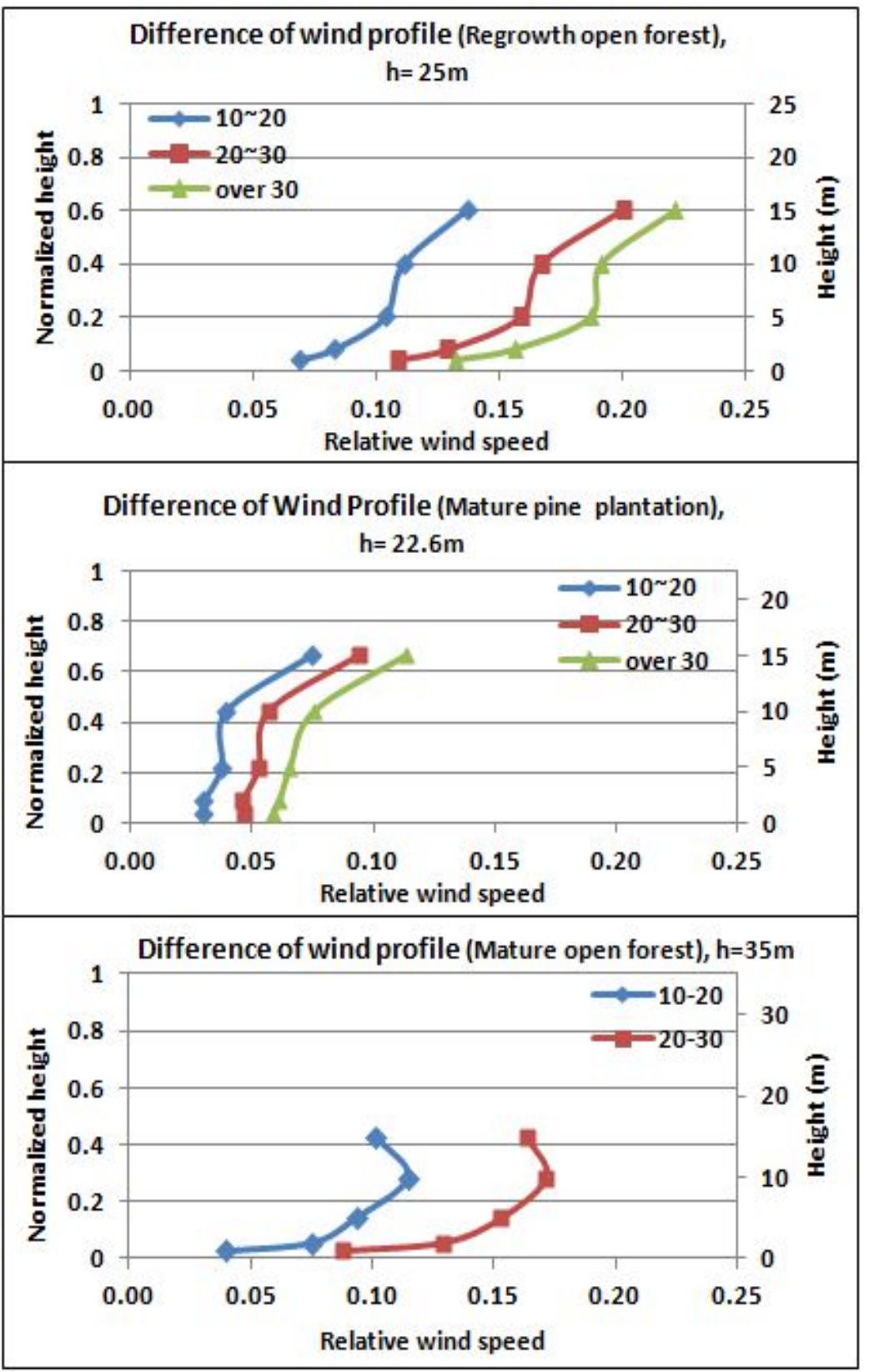

Each forest type was found to have its own distinct vertical wind profile. There was a large amount of variation in the shapes of the wind profiles between the vegetation types (Figure 3). Of note, there was departure from both the open area logarithmic profile (Figure 1) and from a consistent vertical profile (as assumed when using a WRF value). In addition, the magnitude of wind reduction appears to be dependent on the open wind speed; as correspondingly wind profiles and wind reduction magnitudes in the open environment showed no variation with wind speed change (Figure 1).

The magnitude of wind reduction between the different heights was substantial, with differences of over $100 \%$ between the heights of $15 \mathrm{~m}$ and $1 \mathrm{~m}$ in all vegetation types. Thus, as flame heights increase, the fires are likely to be exposed to different wind speeds.

Previous wind models for fire spread predictions have assumed that the variation of winds below the canopy is dependent upon vegetation structure regardless of the values of reference wind speed. Our study found that there was large variation of subcanopy wind speed resulting from changes in the open area wind speed. Higher open wind speeds resulted in higher relative forest wind speeds (a lower wind reduction rate) at all study sites. On the other hand, winds in the open area had the same wind reduction

Figure 3 Difference of wind profiles in three forest types with height and open area wind speeds (10-20 km/hr, 20-30 km/hr and over $30 \mathrm{~km} / \mathrm{hr}$ ). Heights and forest winds were normalized by tree height in each forest type and by open area winds respectively.

rates in all speed ranges (Figure $1)$. Values of relative wind speed in the over $30 \mathrm{~km} / \mathrm{hr}$ range were approximately double those in $10-20 \mathrm{~km} / \mathrm{hr}$ range at all set heights and all study sites, indicating that as wind speeds in the open reference area increase, there is an acceleration of wind penetration. Despite the magnitude of this effect, it is not currently a consideration in fire spread models. The basis of the phenomenon may be the way plants bend and flex under wind loads. Cionco (1972) undertook a wind tunnel study that revealed that the flexibility or rigidity of vegetation greatly 
influences wind flow characteristics. It was found that the level of resistance to wind penetration in forests will decrease as vegetation elements bend over and allow smoother flow under stronger winds. In our results, it is apparent that while the level of wind reduction varied with wind speed, the degree of this variation differed between sites. However, while the magnitude of wind reduction varies with wind speed, the shape of the wind profiles remained relatively consistent.

In the mature open forest, wind speed increased to a height of $10 \mathrm{~m}$, before there was a distinct decrease at $15 \mathrm{~m}$. This may be due to the commonly observed phenomena 'the secondary wind maximum', where winds are able to move relatively freely through the sparse structured tree bole space (Allen 1975; Shaw 1977; Zeng et al. 2000).

Using WRF methods, the typical reduction factor for the evaluated forest types would be 3 in all cases (indicating a reduction of 3:1 from open winds). This is substantially different to the observations, for example, in the mature open forest at low wind speeds, winds were a $30^{\text {th }}$ of the open observations. As wind speeds increased observations approached the WRF value; however in no case was the WRF of 3 actually observed. The WRF is a value that is assumed to be consistent with height and with wind speed. However, inside forests, wind speeds were observed to vary substantially in response to both height and open area wind speed. Consequently the margins of error around the use of a particular WRF are large, in some cases well over an order of magnitude. Fire spread is typically directly proportional to wind speed; consequently without better consideration of forest wind patterns predictions, fire spread predictions can potentially be also prone to such levels of error.

To resolve these issues, more complex representations of forest wind profiles are required. To develop such models, the complex interaction of moving air and vegetation structural attributes must be quantified. In addition, to be operationally useful, the properties of forests important to wind flow must be mapped. While technological and practicality constraints have limited this in the past, recent advances in LIDAR show great potential for the broad scale mapping of vegetation properties. The next component of this project is to quantify vegetation structure and ascertain how this structure defines the vertical wind profile.

\section{CONCLUSIONS}

We found that forest wind profiles were complex and varied substantially with height. In addition, the degree of wind reduction in forests decreases as wind speed increase. These combined effects mean that there could be substantial errors in wind estimates if using a fixed WRF. If these effects are not considered when providing inputs for fire spread simulation, there is the potential for high levels of bias in results. Our study indicates that there is potential to increase the accuracy of fire spread prediction by replacing simple estimates of WRF with dynamic wind speed estimates. We believe our results indicate that this is an important issue that warrants further investigation. In future work, we intend to quantify vegetation structure in detail and develop model to predict forest wind profiles.

\section{ACKNOWLEDGEMENTS}

$\mathrm{K}$. Moon is undertaking this research as part of a $\mathrm{PhD}$. project at the University of Melbourne, funded by a Melbourne Research Scholarship. Additional support was received from the Bushfire Cooperative Research Centre and the Department of Environment and Primary Industries, Victoria.

\section{REFERENCES}

Agee J. (1993). 'Fire ecology of Pacific Northwest forests.'

Albini F.A., Baughman R.G. (1979). Estimating wind speeds for predicting wildland fire behavior. UT: U.S. Department of Agriculture, Forest Service, Intermountain Forest and Range Experiment Station, Ogden.

Allen L. (1975). Line-source carbon dioxide release. Boundary-Layer Meteorology 8(1), 39-79.

Andrews P.L. (2012). Modeling wind adjustment factor and midflame wind speed for Rothermel's surface fire spread model. United States Department of Agriculture/Forest Service, Rocky Mountain Research Station.

Brun C., Artées T.a., Margalef T.a., Cortées A. (2012). Coupling wind dynamics into a DDDAS forest fire propagation prediction system. Procedia Computer Science 9(0), 1110-1118.

Cionco R.M. (1972). A wind-profile index for canopy flow. Boundary-Layer Meteorology 3(2), 255-263. 
Moon et al., Characterising forest wind profiles for utilisation in fire spread models

Cionco R.M. (1978). Analysis of canopy index values for various canopy densities. Boundary-Layer Meteorology 15(1), 81-93.

Cruz M., Matthews S., Gould J., Ellis P., Henderson M., Knight J., Watters J. (2010). 'Fire dynamics in mallee-heath: fuel, weather and fire behaviour prediction in South Australian semi-arid shrublands'. Report A.10.01. Bushfire CRC, Melbourne.

Downey R.P. (2006). Uncertainty in wind turbine life equivalent load due to variation of site conditions. Technical University of Denmark.

Dupont S., Irvine M., Bonnefond J.-M., Lamaud E., Brunet Y. (2012). Turbulent structures in a pine forest with a deep and sparse trunk space: stand and edge regions. Boundary-Layer Meteorology 143(2), 309-336.

Finney M.A. (2004). 'FARSITE, Fire Area Simulator--model development and evaluation.' (US Department of Agriculture, Forest Service, Rocky Mountain Research Station:

Fons W.L. (1940). Influence of forest cover on wind velocity. Journal of Forestry 38(6), 481-486.

Grant P.F., Nickling W.G. (1998). Direct field measurement of wind drag on vegetation for application to windbreak design and modelling. Land Degradation \& Development 9(1), 57-66.

Grant R.H. (1985). The influence of the physical attributes of a spruce shoot on momentum transfer. Agricultural and Forest Meteorology 36(1), 7-18.

McArthur A.G. (1967). 'Fire behaviour in eucalypt forests.' (Commonwealth Forestry and Timber Bureau Leaflet 107: Canberra)

Nelson Jr R.M., Adkins C.W. (1988). A dimensionless correlation for the spread of wind-driven fires. Canadian Journal of Forest Research 18(4), 391-397.

Oke T.R. (1987). 'Boundary Layer Climates.' (Methuen: London)

Oliver H.R. (1971). Wind profiles in and above a forest canopy. Quarterly Journal of the Royal Meteorological Society 97(414), 548-553.

Pereira A.R., Shaw R.H. (1980). A numerical experiment on the mean wind structure inside canopies of vegetation. Agricultural Meteorology 22(3-4), 303-318.

Raynor G.S. (1971). Wind and temperature structure in a coniferous forest and a contiguous field. Forest Science 17(3), 351-363.

Rothermel R.C. (1972). A mathematical model for predicting fire spread in wildland fuels. USDA Forests Service Research Paper, Intermountain Forest and Range Experiment Station.

Shaw R.H. (1977). Secondary wind speed maxima inside plant canopies. Journal of Applied Meteorology 16(5), 514-521.

Smith T.J. (1992). Forest structure. In 'Tropical mangrove ecosystems, coastal estuarine stud.' (Eds A.I. Robertson, D.M. Alongi.) Vol. 41 (AGU: Washington, D. C.)

Stocks B.J., Alexander M.E., Wotton B.M., Stefner C.N., Flannigan M.D., Taylor S.W., Lavoie N., Mason J.A., Hartley G.R., Maffey M.E., Dalrymple G.N., Blake T.W., Cruz M.G., Lanoville R.A. (2004). Crown fire behaviour in a northern jack pine - black spruce forest. Canadian Journal of Forest Research 34(8), $1548-1560$.

Sullivan A.L. (2009). Wildland surface fire spread modelling, 1990-2007. 1: Physical and quasi-physical models. International Journal of Wildland Fire 18(4), 349-368.

Taylor S.W., Wotton B.M., Alexander M.E., Dalrymple G.N. (2004). Variation in wind and crown fire behaviour in a northern jack pine - black spruce forest. Canadian Journal of Forest Research 34(8), 15611576. 
Moon et al., Characterising forest wind profiles for utilisation in fire spread models

Tolhurst K., Shields B., Chong D. (2008). Phoenix: development and application of a bushfire risk management tool. Australian Journal of Emergency Management 23(4), 47.

Zeng P., Takahashi H. (2000). A first-order closure model for the wind flow within and above vegetation canopies. Agricultural and Forest Meteorology 103(3), 301-313. 